\title{
Impactos da Covid-19 na Mobilidade, na Acessibilidade e no Trabalho do Psicólogo do Trânsito
}

\author{
Fábio de Cristo $^{1}$ \\ ${ }^{1}$ Universidade Federal do Rio Grande do Norte, RN, Brasil. \\ Renan da Cunha Soares Júnior ${ }^{2}$ \\ ${ }^{2}$ Universidade Católica Dom Bosco, MS, Brasil.
}

\author{
Karla Garcia Luiz ${ }^{3}$ \\ ${ }^{3}$ Universidade Federal de Santa Catarina, SC, Brasil. \\ Andrea dos Santos Nascimento ${ }^{4}$ \\ ${ }^{4}$ Universidade Federal do Espírito Santo, ES, Brasil.
}

Resumo: Neste artigo, discutem-se os impactos da Covid-19 na mobilidade, na acessibilidade de pessoas com deficiência e no trabalho do psicólogo do trânsito. Em relação à mobilidade, são apontados dados sobre a demanda de viagem nos transportes urbanos e suas repercussões sociais e econômicas, como o desemprego e o incremento do transporte clandestino com o fechamento de empresas de transporte. São discutidos também o uso de transportes sustentáveis como alternativa e o investimento em comunidades locais autossuficientes para diminuir os deslocamentos. Em relação aos impactos na acessibilidade, comentaremos sobre os avanços na legislação e a mudança de cultura visando à concretização das práticas de inclusão. Também exemplificamos como pessoas com deficiência vivenciam riscos adicionais de contrair a Covid-19 nos deslocamentos. Quanto aos impactos no trabalho do psicólogo do trânsito, analisam-se a suspensão das atividades presenciais e seu retorno e como os psicólogos continuaram desempenhando seu trabalho, desde a perícia psicológica para a habilitação e docência, passando pela gestão de projetos e políticas públicas (e.g., educação para o trânsito) e de associações profissionais. As expectativas para o pós-pandemia e os seus aprendizados também são discutidas. Conclui-se que a pandemia da Covid-19 potencializou o contexto, já presente antes da pandemia, de desigualdade estrutural nas cidades, na mobilidade e na acessibilidade, bem como acentuou a necessidade de adaptação dos processos de trabalho da psicologia. Vislumbram-se mudanças e avanços possíveis, priorizando a diversidade da coletividade na busca de soluções que atendam aos mais diversos grupos de pessoas.

Palavras-chave: Pandemia, Mobilidade, Acessibilidade, Transporte, Psicologia do Trânsito.

\section{Impacts of Covid-19 at Mobility, Accessibility and Work of the Traffic Psychologist}

\begin{abstract}
In this article, there is a discussion about the impacts of Covid-19 at the mobility, accessibility of people with disabilities and the work of the traffic psychologist. Concerning to mobility, the data of requests about using urban transportation and social and economic repercussion are emphasize, such as unemployment and illegal transportation increase, resulting in transport companies closure. The employ of the sustainable transportation as an alternative and investment on sustainable local communities to reduce travels are also discussed. Regarding to accessibility impacts, it will be comment about the law advances and the culture changes, with the aim of concretize inclusion practices. It also exemplifies how disable people live with additional risks of contracting Covid-19 when they travel. As for the impacts of traffic psychologist work, the suspension of face-to-face and their return are analyzed, and how those professionals will do their jobs, from psychologist expertise to qualification and
\end{abstract}


teaching, going through projects and public policies management, just as traffic education, and professional association management. Expectations for the post-pandemic and its learning are also discussed. It is concluded that the Covid-19 pandemic has enhanced the context of structural inequality in cities, mobility and accessibility already present before the pandemic, as well as emphasizing the need to adapt psychology's work processes. Changes and possible advances are envisaged, prioritizing the community diversity at the pursuit of solutions that can assist the most diverse group of people.

Keywords: Pandemic, Mobility, Accessibility, Transport, Traffic psychologist.

\title{
Impactos del Covid-19 en la Movilidad, la Accesibilidad y el Trabajo del Psicólogo de Tránsito
}

\begin{abstract}
Resumen:En este artículo, discutimos los impactos del Covid-19 en la movilidad, la accesibilidad para personas con discapacidad y el trabajo del psicólogo de tránsito. En relación a la movilidad, se señalan datos sobre la demanda de viajes en el transporte urbano y sus repercusiones sociales y económicas, como el desempleo y el incremento del transporte ilegal con el cierre de empresas de transporte. También se discute el uso del transporte sostenible como alternativa y la inversión en comunidades locales autosuficientes para reducir los desplazamientos. En cuanto a los impactos en la accesibilidad, comentaremos los avances en la legislación y el cambio de cultura con miras a implementar prácticas de inclusión. También se ejemplifica cómo las personas con discapacidades experimentan riesgos adicionales de contraer el Covid-19 en los desplazamientos. En cuanto a los impactos en el trabajo del psicólogo de tránsito, se analiza la suspensión de las actividades presenciales y su retorno, y cómo los psicólogos continuaron realizando su labor, desde la pericia psicológica hasta la capacitación y docencia, pasando por la gestión de proyectos y políticas públicas (como la educación vial) y la gestión de asociaciones profesionales. Además, se analizan las expectativas para la pospandemia y su aprendizaje. Se concluye que la pandemia de Covid-19 ha potenciado el contexto de desigualdad estructural en las ciudades, la movilidad y la accesibilidad, ya presentes antes de la pandemia, además de enfatizar la necesidad de adecuar los procesos de trabajo de la psicología. Se perciben posibles cambios y avances priorizando la diversidad de la colectividad en la búsqueda de soluciones que atiendan a los más diversos grupos de personas.
\end{abstract}

Palabras clave: Pandemia, Movilidad, Accesibilidad, Transporte, Psicología de Tránsito.

Os dados atuais de infectados por Covid-19 em nosso país sugerem que a enfermidade segue em triste ascensão. O número de mortos continua aumentando em várias cidades e no Brasil como um todo, desde o final de maio de 2020 até o momento. Nesse período, a cada dia, mais de 900 brasileiros perderam a vida, considerando as médias de mortes dos últimos sete dias, tendo chegado a 1.554 de óbitos por dia no mês de julho ${ }^{1}$. A sociedade, altamente impactada, amarga consequências negativas sem precedentes nas diversas áreas, incluindo a mobilidade. Seja ela exercida ou não por meio de veículos, possibilita movermo-nos pelos espaços urbanos/rurais, acessarmos os diversos equipamentos públicos (por exemplo, para lazer) e contribui para nossa qualidade de vida. Se a diminuição ou ausência de deslocamentos pode reduzir a disseminação da enfermidade, pode repercutir em nossa saúde mental, devido ao distanciamento social e ao fechamento temporário de uma região (lockdown) (Perrelli, Telles, Guimarães, \& Cristo, 2020).

${ }^{1}$ Veja dados do consórcio de veículos de imprensa: https://glo.bo/3gjp2Fv 
A problemática dos impactos dessa pandemia é complexa, coexistindo simultaneamente tanto aspectos negativos como a consternação diante das mortes e da dor das pessoas que ficaram com sequelas mesmo após recuperadas, a ansiedade diante das incertezas quanto ao futuro pessoal e da nação, como também a possibilidade de mudarmos para melhor nossa relação com as pessoas, com a cidade e com o trabalho. Por exemplo, a pandemia possibilitou a diminuição (e até mesmo a ausência de registro de uma única ocorrência) de morte de pedestres e de colisões entre os veículos durante a época de maior adesão ao distanciamento social. Na Califórnia (EUA), por exemplo, as colisões caíram para $50 \%$ num período de dois meses (Majoo, 2020). Além disso, os carros deram lugar aos pedestres e aos patins, aos skates e às bicicletas convencionais e elétricas. Com isso, as cidades ficaram mais silenciosas, mesmo as mais agitadas, com um céu visível e relatos de escuta de sons de pássaros, como a homenagear os que se foram.

A análise dos impactos também apresenta contornos sociais, econômicos e políticos que influenciam a mobilidade e que não se podem desprezar. Alguns autores, como Caponi (2020), sugerem que tem havido descontrole da gestão federal brasileira em relação à pandemia em contexto neoliberal. Para a autora, existe relação entre o aumento do número de óbitos e o descaso dos gestores públicos com as questões sociais e a urgência do mercado em manter o lucro. As medidas preventivas de distanciamento social (somadas a muitas outras), na ausência de uma vacina comprovadamente eficaz até o momento, tiveram recepção negativa em um contexto onde, "com quase a metade da população vivendo na informalidade, desemprego e precariedade, não parece fácil impor o isolamento sem criar, ao mesmo tempo, redes socioeconômicas de proteção compensatórias" (Caponi, 2020, p. 209). Na falta da garantia dos direitos humanos, o negacionismo, a rejeição à ciência e o apoio ao criacionismo acabam sendo formas de proteção que os sujeitos encontram para lidar com um sistema que não lhes fornece garantias de sobrevivência (Caponi, 2020).

Esse fenômeno pode ser observado, tal como afirma Uchôa-de-Oliveira (2020), no aumento do fluxo dos entregadores de aplicativos durante a pandemia que, mediados por plataformas digitais, motorizados ou de bicicleta, prestadores de serviços informais considerados serviços essenciais do ramo alimentício e farmacêutico, por exemplo, estiveram bem presentes no dia a dia de muitas famílias. Sem as garantias oficiais de um trabalho formal de carteira assinada, e em meio ao achatamento da legislação trabalhista, o empreendedorismo justificado pelo liberalismo econômico foi uma forma de sustento que esses trabalhadores oportunizaram para si, até mesmo porque houve maior demanda desse serviço devido à manutenção do distanciamento físico e social. Sob a lógica do "seja dono do seu próprio negócio", o trabalhador aprende a ser um empreendedor que "toma para si todos os riscos do seu trabalho" (Uchôa-de-Oliveira, 2020, p. 2). Esse fato promoveu, inclusive, um movimento de greve dos entregadores, de forma a chamar atenção para esse fato e promover a valorização do trabalho, além das garantias trabalhistas.

Considerando esse cenário complexo e entrelaçado, obviamente não esgotado nesses breves apontamentos iniciais, abordaremos, neste artigo, alguns impactos da pandemia da Covid-19 na mobilidade e suas repercussões na acessibilidade de pessoas com deficiência e no trabalho no psicólogo do trânsito, reconhecendo a urgência desse debate na Psicologia brasileira.

No caso específico dos impactos na mobilidade, abordaremos a demanda de viagem nos transportes urbanos e algumas repercussões sociais e econômicas, e o uso de transportes sustentáveis (e.g., a bicicleta) como alternativa no contexto da pandemia. No tocante aos impactos na acessibilidade, comentaremos sobre os avanços na legislação e, para além disso, o imperativo da mudança de cultura, visando a concretização das práticas de inclusão. Também exemplificaremos como as pessoas com deficiência vivenciam riscos adicionais de contrair a Covid-19 nos deslocamentos. Sobre os impactos no trabalho do psicólogo do trânsito, finalmente, analisaremos a suspensão das atividades presenciais e seu retorno, e como os psicólogos continuaram desempenhando seu trabalho, as expectativas para o pós-pandemia e os seus aprendizados (Figura 1).

\section{Impactos da Covid-19 na mobilidade}

Nesta seção, apontaremos dados sobre os impactos na demanda de viagem nos transportes urbanos e algumas repercussões sociais e econômicas, como o desemprego (inclusive para os psicólogos do trânsito) e o incremento do transporte clandestino com o fechamento de empresas de 
transporte. O possível não retorno de parcela dos usuários ao uso dos transportes públicos após a flexibilização também é um fator que contribui para esse cenário. Em seguida, serão discutidos o uso de transportes sustentáveis (e.g., a bicicleta) como alternativa no contexto da pandemia e os investimentos em comunidades locais autossuficientes como um caminho para diminuir os deslocamentos, considerando alguns países como exemplo e os desafios no contexto brasileiro.

\section{Impactos na demanda de viagem nos transportes urbanos, repercussões sociais e econômicas}

A Associação Nacional das Empresas de Transporte Urbano - NTU (2020) apresenta dados que demonstram diminuição de $71 \%$, em média, de demanda de passageiros em relação ao contingente anterior à pandemia. Isso representa um quantitativo de trinta milhões de passageiros a menos realizando viagens por meio de ônibus diariamente em todo o país. Com isso, houve a diminuição média de oferta do serviço em $52 \%$ já no segundo mês da pandemia. Foi necessário esforço para manter o transporte dos trabalhadores dos serviços essenciais, porém houve diminuição de frota e de frequência ao mesmo tempo em que foi necessário manter as condições de segurança exigidas em razão do distanciamento social (e.g., transporte de pessoas em pé, distanciamento dentro dos veículos e lotação máxima permitida). Isso resultou, somente nos primeiros sessenta dias de crise do novo coronavírus, num prejuízo da ordem de $\mathrm{R} \$ 2,1$ bilhões no encerramento de atividades de uma empresa do setor, na perspectiva de falência de mais onze empresas e na suspenção de atividades em três empresas. Foram registradas 1.806 demissões e 9.235 suspensões de contratos de trabalho. Esse cenário aponta, consequentemente, a perda de emprego para inúmeros profissionais, dentre eles os psicólogos que trabalham nas organizações de trabalho do setor de transportes.

Em outro estudo, a Associação Nacional de Transportadores de Passageiros sobre Trilhos ANPTrilhos (2020), entidade que representa os operadores de sistemas de metrô, trem urbano e veículos leves sobre trilhos (VLT) do Brasil, indica que, no primeiro trimestre de 2020, em relação ao mesmo período do ano passado, houve diminuição de $73 \%$ no número de passageiros transportados no país.
Em São Paulo, o decréscimo foi de $43 \%$ no primeiro trimestre e de $74 \%$ no segundo trimestre; no Rio de Janeiro, de $42 \%$ no primeiro e de $74 \%$ no segundo trimestre; e, no Nordeste (média incluindo $\mathrm{BA}, \mathrm{AL}$, $\mathrm{PE}, \mathrm{PB}, \mathrm{RN}$ e CE), correspondeu a menos $46 \%$ de passageiros no primeiro trimestre de 2020 em relação a 2019 , e de menos $76 \%$ no segundo trimestre também em relação ao mesmo período do ano anterior. Em todo o primeiro semestre de 2020, foram transportados apenas 880 milhões de passageiros, contra uma expectativa de 1,550 bilhão de pessoas, representando somente $57 \%$ do que era esperado para o período. Entre março e junho de 2020, a redução de arrecadação no setor de transporte sobre trilhos foi em torno de $\mathrm{R} \$ 3,6$ bilhões no Brasil.

Conforme se observa nesta seção, o incentivo ao uso do transporte público por parte da população enfrenta desafio adicional por conta da pandemia, consequentemente dificultando ainda mais a elaboração de políticas públicas nessa direção. Os psicólogos do trânsito, dentre outros profissionais, podem colaborar com estudos que busquem entender, por exemplo, crenças, atitudes, motivações e percepções tanto dos usuários atuais como daqueles que deixaram de usar transporte público nesses tempos de pandemia.

\section{Possível presença de transporte clandestino com o fechamento de empresas de transporte}

Lindau e Avelleda (2020) enfatizam que, no Brasil, o sistema de transporte público é subsidiado pelos usuários e, com a queda na arrecadação, os governos locais e, também, o federal sofrem pressão pelo auxílio ao setor com recursos para evitar que aconteça um colapso. O retardamento ou a falta dessas ações pode levar ao fechamento de empresas de transporte coletivo, resultando num comprometimento do acesso de cidadãos das periferias à cidade, devido ao corte e ao encerramento de linhas. Com o fim do serviço regulado, poderia ser aberto espaço para mototáxis e lotações em vans informais, maximizando, por sua vez, a presença da circulação de automóveis e de motocicletas, com incremento na poluição do ar, no número de óbitos no trânsito e gerando níveis de congestionamento até então inimagináveis. Dessa forma, procrastinar a tomada de decisão poderá acarretar grandes prejuízos econômicos, sociais e ambientais.

Além disso, estudos sobre as opiniões dos usuários a respeito do retorno ao uso dos transportes 
públicos após a flexibilização sugerem preocupação. Uma pesquisa realizada pelo Banco Interamericano de Desenvolvimento - BID (2020), em parceria com o aplicativo Moovit, entrevistou 33 mil cidadãos em nove cidades da América Latina - Bogotá, Buenos Aires, Cidade do México, Guadalajara, Guayaquil, Montevidéu, Santiago, Rio de Janeiro e São Paulo revelou que, em média, $8 \%$ dos passageiros não pretendem retomar o uso do transporte público, mesmo depois do abrandamento das medidas sanitárias adotadas atualmente. Entre os entrevistados que declararam não estar utilizando transportes públicos durante a semana anterior à realização da pesquisa, $68 \%$ responderam ter intenção de voltar a utilizar transporte público e $23 \%$ dos participantes se declaram ainda indecisos sobre o uso do transporte público em fases posteriores. O número de pessoas que pretendem deixar de utilizar o transporte público foi de $3,6 \%$, refletindo possivelmente a preocupação dos usuários com a propagação e o aumento da contaminação com seu uso.

No Brasil, a maioria dos usuários de transporte público pertence às classes mais vulneráveis economicamente, sendo, respectivamente, $35,8 \%$ integrantes da classe C e 60,8\% das classes D e E. A oferta do serviço foi prejudicada e percebida por $59,2 \%$ dos entrevistados em SP e 53,9\% no RJ, segundo o referido estudo. Em São Paulo e no Rio de Janeiro, $23 \%$ e $24 \%$ das pessoas, respectivamente, alegaram ter usado outros meios para se transportar, corroborando o mencionado por Lindau e Avelleda (2020), de que problemas na oferta dos serviços podem acarretar uma massiva utilização de transporte clandestino.

O uso de transportes sustentáveis e os investimentos em comunidades locais autossuficientes podem ser um caminho para diminuir os deslocamentos. De acordo com Medeiros e Rajs (2020), o distanciamento social já é realidade nos países europeus. Em algumas cidades europeias de grande porte, o uso de bicicletas tem sido incentivado, com maior disponibilidade de ciclovias. As autoras salientam que ainda apresentamos dificuldades para adotar esse tipo de medidas em larga escala no Brasil, pois comumente existem problemas no respeito aos planos diretores e não há priorização da qualidade do espaço público. O que se tem observado é a tendência em apoiar um modelo rodoviarista, com cada vez mais automóveis e veículos utilizados para o transporte individual nas ruas, o que poderá ser maximizado com a volta das atividades à normalidade. Isso devido à tendência de evitar o transporte público por parcela das pessoas com receio de aglomeração. O ciclo das desigualdades tende a se agravar em situações extremas, como a vivenciada durante a pandemia.

A Organização Pan-americana de Saúde - Opas (2018) e a Organização Mundial da Saúde (OMS) têm apontado caminhos por meio da intersetorialidade com a participação de várias entidades e organizações. Antes da pandemia, já havia o desenvolvimento de uma agenda convergente de mobilidade sustentável e saúde norteada por princípios que incluem equidade na mobilidade urbana sustentável, deslocamento urbano seguro e confortável, prioridade para a mobilidade ativa e transporte coletivo eficiente e em condições adequadas, qualidade do ar nas cidades, convergência entre os instrumentos de planejamento em saúde e planejamento urbano e ambiental. Essa discussão precisa ser ampliada aos psicólogos do trânsito. Nesse sentido, no contexto da pandemia, estudos sobre os determinantes do uso da bicicleta e da caminhada (Luiza Neto et al., 2020) têm sido ainda mais relevantes, apontando esses meios como alternativas para evitar aglomerações, além de serem mais saudáveis. Ademais, a pressão dos movimentos sociais, como as associações de ciclistas, é importante nesse processo (e.g., Ciclocidades, em SP, e Rodas da Paz, no DF).

Medeiros e Rajs (2020) ressaltam ainda que, com a flexibilização, tem ocorrido problemas de aglomeração, o que talvez se explique por questões culturais de disponibilidade e gosto pelo contato físico, e, também, a dificuldade em seguir normas de comportamento e organização. Não há formas fáceis de manter esse modelo e garantir distanciamento social, o que parece ser a alternativa é o investimento em uma cultura de comunidades locais autossuficientes, priorizando um modelo de cidade em que as necessidades básicas estejam disponíveis com mais proximidade, diminuindo a necessidade essencial de transporte para a vida cotidiana na urbe.

As diferenças culturais entre América do Sul e Europa podem ser grandes, mas a busca por soluções em momento tão agudo pode ter como norteador o cuidado com a carrocracia (Ludd, 2005; Trói, 2018) vivida atualmente no Brasil. As oportunidades de 
pensar em outras formas democráticas e sustentáveis de organização e utilização do espaço público e da mobilidade podem ser incrementadas pelas necessidades ora presentes, com a busca por caminhos para diminuir as desigualdades tão explícitas durante a pandemia de Covid-19. Nesse caso, não se pode esquecer também das pessoas com deficiência, tema sobre o qual os psicólogos do trânsito devem se debruçar cada vez mais.

\section{Impactos da Covid-19 na acessibilidade}

Nesta seção, abordaremos sobre as pessoas com deficiência e a acessibilidade à cidade e ao transporte no contexto da pandemia. Iniciaremos comentando sobre os avanços na legislação e, para além disso, o imperativo da mudança de cultura, visando a concretização das práticas de inclusão. Em seguida, exemplificaremos riscos adicionais de contrair a Covid-19 nos deslocamentos das pessoas com deficiência (Figura 1).

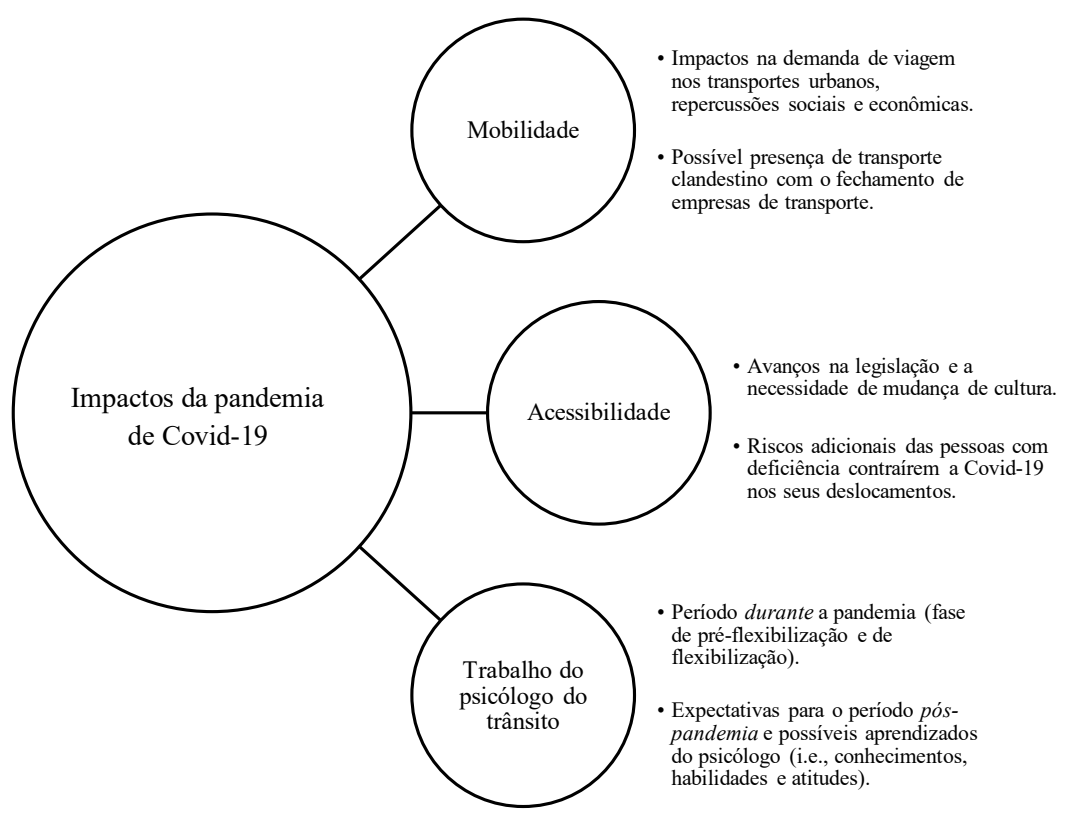

Figura 1

Impactos da pandemia de Covid-19 na mobilidade, na acessibilidade e no trabalho do psicólogo do trânsito.

\section{Avanços na legislação e a necessidade de mudança de cultura}

O distanciamento social e as dificuldades para acessar as cidades já era uma realidade para grande parte das pessoas com deficiência no Brasil. Em nosso país, cerca de $25 \%$ da população tem algum tipo de deficiência (Instituto Brasileiro de Geografia e Estatística, 2010). No entanto, sempre que esse dado é demonstrado, há uma surpresa no número que esse percentual expressa: são quase 50 milhões de brasileiros que vivem a experiência da deficiência. Onde estão essas pessoas?

Embora tenhamos avançado consideravelmente nas últimas décadas na implementação de leis que garantam o acesso de pessoas com deficiência na sociedade, nas mais diversas áreas, estudos apontam que há uma significativa exclusão das pessoas com deficiência, seja na educação, no trabalho, nos serviços de saúde ou nos transportes (Costa, 2020; Medeiros \& Rajs, 2020). Isso porque, embora as leis sejam ferramentas fundamentais para a garantia de direitos, a mudança cultural ocorre de maneira mais lenta do que a elaboração e a aprovação de uma legislação.

As leis do Brasil em relação às pessoas com deficiência acompanham uma perspectiva bastante contemporânea sobre deficiência e estão relacionadas aos direitos humanos. Um exemplo disso é a ratificação da Convenção da Organização das Nações Unidas (ONU) sobre os Direitos das Pessoas com Deficiência, que tem caráter de emenda constitucional desde 2008. A Convenção é um documento de suma importância, pois está assinada por 180 países ao redor do mundo e versa sobre os direitos desse 
grupo social em seus mais variados aspectos da vida. Cabe destacar, ainda, que essa Convenção surgiu de diálogos entre a sociedade civil e a ONU, cujo lema foi "Nada sobre nós, sem nós". Desse modo, preconiza a participação das pessoas com deficiência em tudo aquilo que estiver ligado a sua vida (Decreto $\mathrm{n}^{\circ} 6.949,2009$ ).

Em síntese, a Convenção versa sobre $o$ que os países devem assegurar e, posteriormente, cada país criará sua própria lei para mostrar como a cumprirá. Assim, a Convenção impulsionou a criação da Lei Brasileira de Inclusão da Pessoa com Deficiência (LBI), que entrou em vigor em 2015. A LBI é composta de 127 artigos que garantem os direitos das pessoas com deficiência em esferas como transporte, educação, trabalho, moradia, saúde, direitos sexuais e reprodutivos, acesso à justiça, entre outras.

Especificamente em relação ao transporte, do artigo 46 ao 52, a LBI assegura que todos os meios de transporte e em todas as jurisdições deve estar garantido o acesso às pessoas com deficiência em condições de igualdade com as demais pessoas. Todavia sabemos que esse direito ainda está longe de ser concretizado (Lei no $13.146,2015)$.

Durante a pandemia, ampliaram-se as barreiras impostas para pessoas com deficiência transitarem nas cidades. Além de os transportes terem se tornado um meio escasso de locomoção, tornaram-se um meio de alta contaminação de coronavírus.

\section{Riscos adicionais das pessoas com deficiência contraírem a Covid-19 nos seus deslocamentos}

É oportuno mencionar, inicialmente, que, antes da pandemia, as pessoas com deficiência já enfrentavam barreiras para acessar os mais variados tipos de transporte no Brasil por falta de acessibilidade. Conta-se com pouco espaço nos transportes e com frota pouco adequada às reais necessidades das pessoas com deficiência, seja no modo terrestre, ferroviário, aquaviário ou aéreo.

Nesse sentido, as pessoas com algum tipo de deficiência correm riscos adicionais de contrair a Covid-19 nos seus deslocamentos. É o caso das pessoas com deficiência visual, por sua maior necessidade de toque. De modo geral, elas utilizam com frequência o tato para se guiar, para ler informações em Braille e podem utilizar equipamentos como bengalas ou cão-guia. Essa necessidade de contato físico e o uso de apoios podem ser situações e objetos propensos à contaminação. Além disso, pela própria característica da deficiência, essas pessoas terão dificuldade de saber se as demais estão de máscara e/ou respeitando o distanciamento social em prol de sua segurança.

As pessoas que utilizam cadeira de rodas manual são outro exemplo. Nesse caso, o contato do pneu com o solo infectado pode, por sua vez, contaminar as mãos dessas pessoas, aumentando o risco de contrair a Covid-19. Para uma pessoa com essa necessidade ou perfil, higienizar as mãos e a cadeira o tempo inteiro, além de trabalhoso, pode ser inviável, uma vez que precisará tocar a própria cadeira constantemente ao menor deslocamento.

Para as pessoas surdas, por sua vez, o uso de máscaras impossibilita a leitura labial para aquelas que utilizam desse recurso de comunicação (Medeiros \& Rajs, 2020) e, consequentemente, dificulta, por exemplo, a aquisição de informações para se locomover com autonomia, notadamente em lugares pouco ou totalmente desconhecidos. Essas situações indicam que precisamos aprofundar os estudos sobre deficiência, seja na formação de base dos psicólogos, seja no treinamento de outros profissionais que, invariavelmente, depararão com pessoas com deficiência em suas práticas. Pessoas surdas que fazem leitura labial, por exemplo, precisam usar e precisam que seus interlocutores também usem máscaras do tipo face shield (transparentes). E não podem ser barradas nos estabelecimentos, em transportes ou espaços públicos por uma impossibilidade de comunicação imposta pelas máscaras tradicionais de pano.

Por fim, o que percebemos é que esse momento tão adverso de pandemia serve como lente de aumento para processos de exclusão os quais as pessoas com deficiência já vivenciavam. Adicionalmente, a pandemia e o distanciamento social intensificaram as barreiras já existentes em muitos contextos. Para as pessoas com deficiência, o período que seguirá o atual só poderá ser chamado de "novo normal" se houver uma mudança significativa nos modos como os serviços, incluindo o de transportes, serão ofertados.

Os psicólogos, de maneira geral, e os do trânsito, de modo específico, devem estar atentos a essas questões, notadamente os que estão envolvidos nas políticas públicas de planejamento urbano e infraestrutura de transportes, além daqueles atuantes nas empresas prestadoras de serviços de transportes. 
Na próxima seção, caracterizaremos, então, os impactos no trabalho desses psicólogos nos diversos setores (público e privado), considerando os períodos antes e durante a pandemia de Covid-19, buscando identificar, por exemplo, o que mudou em suas atividades principais. Em seguida, serão discutidas algumas expectativas e possíveis aprendizados do psicólogo, no tocante a seu trabalho, para o período pós-pandemia (Figura 1).

As seguintes perguntas guiarão nossa análise: houve suspensão das atividades presenciais? Se houve, já retornaram? Se não, como os psicólogos continuaram desempenhando seu trabalho? Quais as expectativas sobre seu trabalho no pós-pandemia? Será que houve aprendizados no período (i.e., aquisição de novos conhecimentos, habilidades e atitudes)?

\section{Impactos da Covid-19 no trabalho no psicólogo do trânsito}

No período antes da pandemia, havia o predomínio das ações presenciais nas atividades dos psicólogos do trânsito. Por exemplo, na perícia psicológica, as ações se caracterizavam pela avaliação de candidatos à obtenção da CNH e motoristas que solicitam renovação, adição e mudança de categoria da $\mathrm{CNH}$. Existiam vários atendimentos, com etapas de testagem que ocorriam em grupos (e.g., dez pessoas). No caso da fiscalização desses serviços das clínicas credenciadas, por sua vez, os psicólogos fiscais se deslocavam para o local em equipe.

No caso dos docentes e orientadores de estágio na graduação, as aulas e as supervisões, por exemplo, eram, em geral, todas presenciais, inclusive as atividades de estágio dos estudantes, como a educação para o trânsito nas escolas. Na gestão de projetos e políticas públicas, havia o atendimento ao público, reuniões para as ações educacionais nas ruas e palestras nas escolas. Para as atividades de gestão de associação profissional, por sua vez, havia viagens e reuniões com diretores, representantes de outras entidades e políticos para defender e disseminar as pautas da entidade nos locais próprios para deliberação política (i.e., gabinetes de deputados e senadores e salas de comissões).

Com a chegada da pandemia, os psicólogos do trânsito experienciaram, como outros profissionais, rápidas mudanças em seu cotidiano familiar, laboral, social e econômico. Como os psicólogos estão exercendo suas atividades durante a pandemia que vivenciamos atualmente?

\section{Período durante a pandemia}

Pode ser dividido, didaticamente, em duas fases: a pré-flexibilização, caracterizado pela maior adesão ao distanciamento social e pela suspensão temporária das atividades presenciais, e a flexibilização, com a volta gradual de atividades, incluindo as presenciais sob alguns condicionantes, conforme decretos municipais/estaduais (e.g., com base no número de infectados e quantidade de vagas de leitos de UTI). Ressalta-se, todavia, que a flexibilização ainda não se configura irrestrita, posto que, em algumas atividades, os psicólogos ainda permanecem distanciados, porém trabalhando no formato remoto. Paralelamente, alguns deles, além de distanciados, permaneceram com suas atividades suspensas por um largo período.

Por exemplo, na perícia psicológica, houve suspensão temporária de todas as atividades (presenciais e remotas) até cinco meses depois do início da pandemia (de março a julho) em diversas cidades. A impossibilidade da continuidade de maneira remota ou híbrida (combinação de atividade presencial e remota) esbarrou na natureza da avaliação psicológica e na disponibilidade de poucos testes psicológicos válidos para tal forma de uso. Em consequência, isso gerou prejuízos financeiros em função dos custos de manutenção dos espaços e da ausência de receita no período de suspensão. A fiscalização desses serviços das clínicas credenciadas também teve as atividades suspensas e tende a voltar presencialmente.

Na educação para o trânsito, houve suspensão temporária das atividades presenciais, por conta da aglomeração que provocam, por exemplo, nas escolas. O desafio consiste em planejar ações pedagógicas por meio das novas tecnologias, dentre outras formas possíveis de realização dessa atividade no novo contexto. No caso dos docentes e orientadores de estágio na graduação, as aulas, os estágios e as supervisões foram suspensas temporariamente, de março a junho, até a Portaria no 544/2020 do Ministério da Educação, que dispõe sobre a substituição das aulas presenciais por aulas em meios digitais, enquanto durar a situação de pandemia do novo coronavírus, ou até 31 de dezembro de 2020 e, posteriormente, o ensino remoto foi ampliado até o final do ano de 2021. Neste caso, tem havido a volta das atividades, porém de maneira remota, não presencial (Conselho Federal de Psicologia \& Associação Brasileira de Ensino de Psicologia, 2020). Nas universidades federais, as aulas 
remotas têm provocado relevantes debates sobre temas como saúde mental, precarização do ensino e do trabalho, e igualdade de acesso ao ensino remoto ${ }^{2}$.

Outros psicólogos do trânsito, ainda que distanciados, não tiveram suas atividades suspensas; passaram ao trabalho domiciliar ou home office com atividades on-line. Esses profissionais tiveram de se adaptar rapidamente para ajustar sua vida familiar e laboral no mesmo espaço físico, além de rapidamente desenvolver competências mínimas no uso sistemático de novas tecnologias (e.g., programas de computador para reuniões, produção de material audiovisual e compartilhamento de dados) para dar prosseguimento a suas atividades. Por meio delas, tem sido possível, por exemplo, elaborar textos e documentos, realizar reuniões virtuais e lives em plataformas digitais - entre elas destacamos Instagram, Facebook e YouTube - para debater temas da área. Em relação ao uso dessas redes sociais virtuais, cabe destacar que, em se tratando de pessoas com deficiência, nem todas as plataformas são acessíveis e nem todo público é ouvinte/vidente, o que acaba gerando uma frágil e refutável sensação de inclusão digital.

O retorno das atividades presenciais tem sido caracterizado pela adoção de estratégias e medidas preventivas, como plantões, interrupção total do atendimento direto ao público, atendimento parcial com quantidade de público e de horários de serviço reduzidos, presença mínima de servidores por setor, a fim de que diminua a possibilidade de contágio da doença. Esses protocolos precisam ser de fato acompanhados para que se verifique sua correta aplicação. O retorno de atividades presenciais da perícia tem ocorrido com cuidados específicos, em razão do receio do público quanto aos novos protocolos de atendimento, limitando-se a quantidade de agendamentos e de atendimentos. A redução dos atendimentos foi uma das medidas de segurança, por outro lado, as clínicas continuam a ter dificuldades de se manter devido à pouca receita no período de flexibilização.

O período da pandemia tem sido caracterizado por um conjunto de mudanças no trabalho do psicólogo do trânsito que não são homogêneas. O retorno das atividades (remotas ou presenciais) depende, portanto, do ajuste dos profissionais e das atividades às tecnologias, configurando maior benefício para a população. Isso tudo ao mesmo tempo em que têm de sobreviver a uma pandemia que já matou mais de cem mil pessoas no Brasil, até agosto deste ano, e tem provocado tanta mudança em aspectos que são centrais em nossa vida, como família, trabalho e lazer. Desse modo, esse profissional tem de manter sua saúde física e mental, além de incorporar hábitos rigorosos de higiene e limpeza.

As tecnologias diminuem o impacto do distanciamento social por meio dos contatos virtuais, estes também desafiantes, notadamente porque estamos ainda aprendendo a dialogar num novo ritmo, que é alterado dependendo da quantidade de pessoas e da qualidade da conexão, dentre outras variáveis, tais como o desafio de adaptar essas tecnologias acessíveis para pessoas com deficiência. Isso se torna ainda mais desafiante considerando que, no contexto brasileiro, nas relações no trabalho e no cenário político, as relações tendem a ser presenciais e pessoalizadas.

\section{Expectativas para o período pós-pandemia e possíveis aprendizados do psicólogo}

Em alguns casos, o contato presencial ainda será fundamental. Por exemplo, na perícia psicológica e nas atividades de educação para o trânsito, como palestras e ações de rua; e nas aulas da universidade, notadamente nos estágios. Porém, pelo menos até a descoberta da vacina, os protocolos de biossegurança, isto é, um conjunto de ações destinadas a prevenir, controlar, mitigar ou eliminar riscos da Covid-19, permanecerão. Destacam-se o distanciamento social, os hábitos de higienização das mãos, alimentos e o cuidado na limpeza dos materiais e equipamentos (incluem-se aqui os instrumentos da avaliação psicológica - lápis, caneta, borrachas, pranchas, entre outros). As instituições públicas, como as universidades, enfrentarão desafios adicionais para atender aos referidos protocolos e às demandas de acessibilidade em ambiente virtual (legendagem, audiodescrição e intérpretes de Libras), uma vez que sofrem constantes reduções orçamentárias há anos.

A chegada da vacina trará menos receio e mais segurança na prestação dos serviços e, consequentemente, nas relações sociais. Em outros casos, a necessidade do contato presencial será ponderada e, possivelmente, haverá maior adesão ao uso da

\footnotetext{
${ }^{2}$ Veja o webinário da Academia Brasileira de Ciências: http://www.abc.org.br/evento/webinarios-da-abc-11/
} 
tecnologia, sendo mais incorporada ao cotidiano profissional, como o ensino remoto e ensino a distância, seja com o uso de tutores ou por autoinstrução. Arriscamos na previsão de que a pesquisa científica será largamente realizada de maneira on-line.

Será que aprendemos alguma coisa nesse período de pandemia que sirva para além dela? A pandemia, por um lado, intensificou problemas já existentes concernentes às precariedades das condições de trabalho de muitos profissionais e profissões, não sendo diferente para alguns psicólogos do trânsito. Por exemplo, nas condições materiais e na estrutura física do local (e.g., alguns serviços de psicologia nos departamentos estaduais de trânsito e nas universidades federais). Assim, o profissional está tendo que desenvolver atividades remotamente e/ou presencialmente, porém sem os investimentos necessários (seja antes ou durante a pandemia) para uma adequada e cuidadosa prestação de serviço. Aprendemos, também, que precisamos avançar na informatização de alguns procedimentos de avaliação psicológica, como a testagem ou parte dela, e na discussão de formas alternativas de avaliação (considerando perdas e ganhos potenciais) para que possamos prosseguir com a prática, desde que constatado o benefício à sociedade. Precisamos desenvolver ainda nossas melhores práticas da avaliação psicológica nesse contexto de pandemia (Conselho Federal de Psicologia, 2020), considerando também a acessibilidade das pessoas com deficiência, pois nossas avaliações continuam predominantemente aplicáveis apenas em quem ouve, enxerga, segura caneta, entre outras especificidades.

Numa perspectiva otimista, por outro lado, acreditamos que outros aprendizados estão sendo possíveis. Alguns deles relativos às atitudes pessoais com influência no trabalho (e.g., disposição para repensar o estilo e o ritmo de vida, para adquirir autoconhecimento para lidar com as relações no trabalho, promover o autocuidado e manejar o estresse). Outros concernentes às novas habilidades no uso de recursos tecnológicos (e.g., compartilhamento de documentos e ferramentas de videoconferência considerando ainda as questões éticas e técnicas concernentes ao trabalho) que, por sua vez, podem continuar sendo úteis e alcançar maior número de pessoas (e.g., desenvolvimento das atividades pedagógicas e educação para o trânsito).

Os psicólogos do trânsito têm contado, nos últimos meses, com lives, transmissões on-line e debates públicos realizados pelo sistema conselhos de psicologia, pelas instituições formadoras na área e pelos próprios profissionais em um esforço coletivo de dar sentido ao trabalho da Psicologia, enfocando as possibilidades, os avanços e os limites da intervenção profissional nesse contexto que ainda se apresentava.

Observamos um aumento considerável de interações virtuais promovidas gratuitamente por empresas privadas, como editoras de livros e testes, bem como por entidades profissionais, como a Associação Brasileira de Psicologia de Tráfego (Abrapsit) e a Associação Brasileira de Psicologia Ambiental e Relações Pessoa-Ambiente (Abrapa), para citar algumas relacionadas à área de trânsito e transporte; e em um sentido mais amplo, como é a área da avaliação psicológica, mencionamos o Instituto Brasileiro de Avaliação Psicológica (Ibap), o Instituto Brasileiro de Neuropsicologia e Comportamento (IBNeC) e a Associação Brasileira de Rorschach e Métodos Projetivos (ASBro).

Tem sido possível, ainda, nesse contexto, para parcela de profissionais, obter novos conhecimentos tanto sobre a área de trânsito, transporte e mobilidade em si (e.g., pesquisas e ensaios) quanto de áreas afins (e.g., epidemiologia, estatística e saúde mental). Diversas áreas de atuação da psicologia - seja de educação, saúde mental, psicoterapia, hospitalar, emergências e desastres - enfatizaram os cuidados com a população, com os trabalhadores da saúde, com as políticas públicas e sociais sobre o uso da tecnologia e das ferramentas virtuais e também sobre a formação em psicologia especificamente nesse contexto pandêmico (Sá-Serafim, Do Bú, \& LimaNunes, 2020; World Health Organization, 2020). Foi crescente o número de notas informativas e cartilhas (e.g., da OMS, da Opas, do Ministério da Saúde e da Fundação Oswaldo Cruz), bem como de publicações técnicas para a área da saúde em revistas nacionais e internacionais, muitas delas liberadas gratuitamente por vários meses.

\section{Conclusões}

A pandemia de Covid-19 tem proporcionado momentos de angústias e sofrimentos diversos, mas também de reflexão, novas práticas e oportunidades, entre elas a reflexão sobre o uso dos carros, do transporte público e dos espaços públicos de forma mais inclusiva e igualitária. No que tange 
aos processos de trabalho e à ocupação do espaço público por trabalhadores, observou-se uma constante precarização do trabalho de entregadores mediados pelas plataformas digitais. Esse fato chegou a apresentar um coletivo organizado de resistência a essa precarização.

Os profissionais de psicologia do trânsito, como de outras áreas, têm tido seu trabalho afetado durante a pandemia, principalmente em função do distanciamento social e da suspensão temporária das atividades presenciais. $\mathrm{O}$ retorno dessas atividades tem sido caracterizado pela adoção de estratégias e medidas preventivas, como os protocolos de biossegurança, que também devem prever as especificidades das pessoas com deficiência. No pós-pandemia, embora a necessidade do contato presencial seja ponderada, culminando, talvez, em maior adesão ao uso da tecnologia, existem situações em que tal contato ainda será fundamental, como as perícias psicológicas no processo de habilitação.

Adicionalmente, os psicólogos do trânsito vêm buscando se aproximar de questões que se apresentaram no contexto de paralisação do trabalho, as mudanças de normativas e a adaptação da vida cotidiana. Nesse cenário, é urgente que a Psicologia, como ciência que pensa na totalidade do ser humano, observe e proponha um novo olhar para o acolhimento das demandas das pessoas com deficiência no Brasil, tendo em vista a perspectiva das próprias pessoas com deficiência, de maneira transversal, equitativa e pautada em uma ideia de direitos humanos.

A expectativa para o cenário pós-pandemia é de que existam grandes desafios na modificação de um sistema já excludente e desequilibrado de mobilidade. A pandemia expôs de forma ampla esse sistema que parece perverso e insustentável em várias áreas. Não será possível retornar ao que se tinha antes, sendo necessária a reinvenção da política e da cidadania de forma geral e de maneira redobrada nos espaços em que circulam pessoas com deficiências e suas singularidades (Gertner \& Vasconcellos, 2020).

Espera-se que o fato de a pandemia de Covid-19 ter maximizado conflitos e dificuldades em relação aos contextos da mobilidade e acessibilidade já presentes na pré-pandemia seja um potencializador para que haja efetivamente uma reflexão social democrática com a priorização coletiva da busca de soluções. Estamos em meio a uma crise global sem precedentes, e a saída para isso pode estar na coletividade e na democratização das instâncias de decisão. São de suma importância as contribuições dos psicólogos do trânsito para a diminuição do sofrimento mental e a promoção da qualidade de vida.

\section{Referências}

Associação Nacional de Empresas de Transportes Urbanos (NTU). (2020). Covid-19 e o transporte público por ônibus: Impactos no setor e ações realizadas. https://www.ntu.org.br/novo/upload/Publicacao/Pub637280058369726793.pdf

Associação Nacional dos Transportadores de Passageiros sobre Trilhos (ANPTrilhos). (2020). Balanço do Setor Metroferroviário $2^{o}$ Trimestre de 2020. https://anptrilhos.org.br/wp-content/uploads/2020/07/anptrilhosbalanc\%CC\%A7o-2trimestre-2020.pdf

Banco Interamericano de Desenvolvimento (BID). (2020). O uso do transporte público na América Latina durante a Pandemiada Covid-19.https://moovit.com/wp-content/uploads/2020/06/20.06.22-Pesquisa-BID-em-parceriacom-Moovit-mostra-que-transporte-p\%C3\%BAblico-segue-indispens\%C3\%Alvel-mesmo-na-pandemia.pdf

Caponi, S. (2020). Covid-19 no Brasil: Entre o negacionismo e a razão neoliberal. Estudos Avançados, 34(99), $209-224$. https://doi.org/10.1590/s0103-4014.2020.3499.013

Conselho Federal de Psicologia. (2020). Cartilha de boas práticas para avaliação psicológica em contextos de pandemia. https://site.cfp.org.br/wp-content/uploads/2020/08/clique-aqui.pdf

Conselho Federal de Psicologia, \& Associação Brasileira de Ensino de Psicologia. (2020). Práticas e estágios remotos em psicologia no contexto da pandemia da Covid-19: Recomendações.

Costa, L. S. (2020). A vida da pessoa com deficiência: Reflexões legadas do distanciamento social. In A. Mendes, A. B. Vinagre, A. Amorim, E. Chaveiro, K. Machado, L. C. F. Vasconcellos, \& S. Gertner (Orgs.), Diálogos sobre acessibilidade, inclusão e distanciamento social: Territórios existenciais na pandemia (pp. 10-11). Fiocruz. http://www.ideiasus.fiocruz.br/portal/publicacoes/livros/Livro_Dialogos_sobre_Acessibilidade_Inclusao_e_ Distanciamento_Social_1ed.pdf 
Decreto $n^{\circ}$ 6.949. (2009, 25 de agosto). Promulga a Convenção Internacional sobre os Direitos das Pessoas com Deficiência e seu Protocolo Facultativo, assinados em Nova York, em 30 de março de 2007. http://www.planalto. gov.br/ccivil_03/_ato2007-2010/2009/decreto/d6949

Gertner, S. R. C. B., \& Vasconcellos, L. C. F. (2020). Trabalho, inclusão e acessibilidade no pós-pandemia: Para onde vamos? In A. Mendes, A. B. Vinagre, A. Amorim, E. Chaveiro, K. Machado, L. C. F. Vasconcellos, \& S. Gertner (Orgs.), Diálogos sobre acessibilidade, inclusão e distanciamento social: Territórios existenciais na pandemia (pp. 21-23). Fiocruz. http://www.ideiasus.fiocruz.br/portal/publicacoes/livros/Livro_Dialogos_sobre_ Acessibilidade_Inclusao_e_Distanciamento_Social_led.pdf

Instituto Brasileiro de Geografia e Estatística (IBGE). (2010). Censo Demográfico 2010: Características gerais da população, religião e pessoas com deficiência. https://biblioteca.ibge.gov.br/index.php/ biblioteca-catalogo?view=detalhes \&id=794

Lei $n^{\circ}$ 13.146. (2015, 6 de julho). Institui a Lei Brasileira de Inclusão da Pessoa com Deficiência (Estatuto da Pessoa com Deficiência). http://www.planalto.gov.br/ccivil_03/_ato2015-2018/2015/lei/113146

Lindau, L. A., \& Avelleda, S. (2020). Nova mobilidade urbana. Valor Econômico. https://www.fne.org.br/upload/ Nova_mobilidade_urbana__Opini\%C3\%A3o__Valor_Econ\%C3\%B4mico.pdf

Ludd, N. (Org.). (2005). Apocalipse motorizado: A tirania do automóvel em um planeta poluído. Conrad.

Luiza Neto, I., Matsunaga, L. H., Machado, C. C., Günther, H., Hillesheim, D., Pimentel, C. E., Vargas, J. C., \& D’Orsi, E. (2020). Psychological determinants of walking in a Brazilian sample: An application of the Theory of Planned Behavior. Transportation Research Part F, 73, 391-398.

Majoo, F. (2020, July 9). I've seen a future without cars, and it's amazing. Why do American cities waste so much space on cars? The New York Times. https://www.nytimes.com/2020/07/09/opinion/sunday/ban-cars-manhattan-cities.html

Medeiros, A. P., \& Rajs, S. (2020). As cidades e a pandemia: Efeitos, desafios e transformações. In A. Mendes, A. B. Vinagre, A. Amorim, E. Chaveiro, K. Machado, L. C. F. Vasconcellos, \& S. Gertner (Orgs.), Diálogos sobre acessibilidade, inclusão e distanciamento social: Territórios existenciais na pandemia (pp. 6-9). Fiocruz. http:/ / www.ideiasus.fiocruz.br/ portal/publicacoes/livros/Livro_Dialogos_sobre_Acessibilidade_Inclusao_e_Distanciamento_Social_led.pdf

Organização Pan-Americana da Saúde. (2018). Trânsito: Um olhar da saúde para o tema. Opas. https://iris.paho.org/ bitstream/handle/10665.2/49709/9789275720387_por.pdf?sequence=1 \&isAllowed=y

Perrelli, M. T., Telles, T. C. B., Guimarães, J. B., \& Cristo, F. (2020). Contribuição da psicologia na gestão integral de riscos e desastres, no esporte, no trânsito e nas relações pessoa-ambiente em um cenário de pandemia. In D. R. C. Bentivi (Org.), Retrato da psicologia brasileira no cenário da Covid-19 (Vol. 3, pp. 51-66). Artmed. https://www.sbpot.org.br/noticias/retrato-da-psicologia-brasileira-no-cenario-da-covid-19-ebook-do-volume-3/

Sá-Serafim, R., Do Bú, E., \& Lima-Nunes, A. (2020). Manual de diretrizes para atenção psicológica nos hospitais em tempos de combate ao Covid-19. Revista Saúde \& ciência Online, 8(2), 1-24. https://www.researchgate.net/ publication/340315850_Manual_de_Diretrizes_para_Atencao_Psicologica_nos_Hospitais_em_Tempos_de_ Combate_ao_COVID-19

Trói, M. (2018). Carrocracia: Fluxo, desejo e diferenciação na cidade. Periódicus, 8(1), 270-298.

Uchôa-de-Oliveira, F. M. (2020). Saúde do trabalhador e o aprofundamento da uberização do trabalho em tempos de pandemia. Revista Brasileira de Saúde Ocupacional, 45, e22. https://doi.org/10.1590/2317-6369000012520

World Health Organization. (2020). Mental health and psychosocial considerations during Covid-19 outbreak. https://www.who.int/docs/default-source/coronaviruse/mental-health-considerations.pdf?sfvrsn=6d3578af_2

\section{Fábio de Cristo}

Doutor em Psicologia Social, do Trabalho e das Organizações, docente da Universidade Federal do Rio Grande do Norte, Faculdade de Ciências da Saúde do Trairi, Santa Cruz - RN. Brasil

E-mail: fabiodecristo@gmail.com

(1) http://orcid.org/0000-0001-5188-0376

\section{Renan da Cunha Soares Júnior}

Doutorando em Psicologia da Saúde na Universidade Católica Dom Bosco (UCDB), Campo Grande - MS. Brasil.

E-mail: renanjr@gmail.com

(1) https://orcid.org/0000-0001-7477-6141 


\section{Karla Garcia Luiz}

Doutoranda em Psicologia Social na Universidade Federal de Santa Catarina (UFSC), Florianópolis - SC. Brasil.

E-mail: karla.garcia.luiz@hotmail.com

(1) https://orcid.org/0000-0002-5066-3764

Andrea dos Santos Nascimento

Doutora em Psicologia, Docente do Departamento de Psicologia da Universidade Federal do Espírito Santo, Vitória - ES. Brasil.

E-mail: andreanas@gmail.com

(1) https://orcid.org/0000-0002-1381-9256

Agradecimentos a Ingrid Luiza Neto (UDF e UnB), Marlene Alves da Silva (Orient Consultoria), Uliana Fernandes de Oliveira (Detran-RN) e Juliana de Barros Guimarães (ABRAPSIT e Detran-PE) por colaborarem nas reflexões da seção "Impactos da Covid-19 no trabalho no psicólogo do trânsito".

Endereço para envio de correspondência:

Faculdade de Ciências da Saúde do Trairi (FACISA/UFRN). Rua Vila Trairi, S/N, sala 09, Centro. CEP: 59200-000.

Santa Cruz - RN. Brasil.

Recebido 28/08/2020

Aceito 28/08/2020

Received 08/28/2020

Approved 08/28/2020

Recibido 28/08/2020

Aceptado 28/08/2020

Como citar: Cristo, F, Soares Jr., R. C., Luiz, K. G., \& Nascimento, A. S. (2020). Impactos da Covid-19 na Mobilidade, na Acessibilidade e no Trabalho do Psicólogo do Trânsito. Psicologia: Ciência e Profissão, 40, 1-13. https://doi.org/10.1590/1982-3703003242863

How to cite: Cristo, F., Soares Jr., R. C., Luiz, K. G., \& Nascimento, A. S. (2020). Impacts of Covid-19 at mobility, accessibility and work of the traffic psychologist. Psicologia: Ciência e Profissão, 40, 1-13.

https://doi.org/10.1590/1982-3703003242863

Cómo citar: Cristo, F., Soares Jr., R. C., Luiz, K. G., \& Nascimento, A. S. (2020. Impactos del Covid-19 en la mobilidad, la accesibilidad y el trabajo del psicólogo de tránsito. Psicologia: Ciência e Profissão, 40, 1-13. https://doi.org/10.1590/1982-3703003242863 